\title{
Penerapan Blockchain dan Kriptografi untuk Keamanan Data pada Jaringan Smart Grid
}

\author{
Hafizh Fianto Putra, Wirawan, dan Ontoseno Penangsang \\ Departemen Teknik Elektro, Fakultas Teknologi Elektro, Institut Teknologi Sepuluh Nopember (ITS) \\ e-mail: ontosenop@ee.its.ac.id
}

\begin{abstract}
Abstrak-Smart city adalah sebuah konsep kota yang mengandalkan teknologi Internet of Things (IoT) untuk membantu meningkatkan kualitas kota tersebut. Smart grid adalah salah satu komponen dari smart city yang memperkenalkan komunikasi dua arah antara pelanggan dengan perusahaan penyedia listrik. Salah satu masalah yang dapat terjadi pada jaringan smart grid adalah data pelanggan yang jatuh ke pihak yang tidak bertanggungjawab karena saluran transmisi yang tidak aman. Oleh karena itu, penggunaan blockchain dan kriptografi dapat diterapkan pada jaringan smart grid untuk menyelesaikan masalah tersebut. Blockchain memberikan keamanan tambahan untuk penyimpanan data pada pusat pengatur jaringan dan kriptografi memberikan kerahasiaan dan autentikasi pada pertukaran data dalam jaringan. Sistem yang baru diciptakan ini harus bisa menyesuaikan frekuensi pengambilan data pada jaringan smart grid. Penelitian ini bertujuan untuk mengetahui waktu komputasi yang dibutuhkan dari kedua proses tersebut dengan menyusun suatu simulasi jaringan smart grid. Simulasi dalam penelitian ini dilakukan dengan menggunakan aplikasi MATLAB dan tersusun dari dua program utama, yaitu program kriptografi menggunakan algoritma RSA dan program pembuatan blockchain sederhana. Hasil yang didapatkan menunjukkan bahwa rentang waktu komputasi RSA pada suatu jaringan smart grid lebih cepat dari frekuensi pengambilan data yang ditentukan, yaitu sebesar satu menit. Sementara itu, rentang waktu penyusunan blockchain dengan ketentuan tertentu tidak dapat memenuhi persyaratan yang sama.
\end{abstract}

Kata Kunci-Blockchain, Kriptografi, MATLAB, RSA, Smart Grid.

\section{PENDAHULUAN}

SMART grid adalah sebuah jaringan nasional yang $S_{\text {menggunakan teknologi informasi pada kelistrikan agar }}$ efisien, dapat diandalkan, dan aman [1]. Smart grid sejatinya adalah salah satu komponen dari smart city, kota yang menerapkan Internet of Things (IoT) untuk meningkatkan kualitas kota dan rakyat yang tinggal di kota tersebut. Pada jaringan smart grid, akan ada pertukaran data secara dua arah antara pengguna listrik dengan perusahaan penyedia listrik. Contoh data yang dapat diambil dari meteran listrik pengguna adalah nilai tegangan, arus, dan power factor [2].

Sebagai contoh, Umass Smart yang dikeluarkan oleh salah satu laboratorium di University of Massachusetts Amherst mengoleksi data tiap satu menit berupa sepuluh digit unix timestamp dan nilai watt yang terukur oleh meteran listrik [3]. Sementara itu, Customer Behavior Trials (CBT) yang dikeluarkan oleh badan regulator di Irlandia, Commission for Regulation of Utilities (CRU) menunjukkan tiga informasi pada hasil pengukuran smart meter yang berupa nomor identifikasi meteran, kode yang menunjukkan tanggal dan waktu, dan konsumsi listrik selama interval 30 menit [4].

Masalah yang dapat terjadi pada smart grid adalah data pelanggan yang jatuh ke pihak yang tidak bertanggungjawab karena saluran transmisi yang tidak aman [5]. Data yang didapatkan tersebut dapat disalahgunakan sehingga merugikan pelanggan maupun perusahaan penyedia listrik.

Penggunaan blockchain dan kriptografi dapat diterapkan pada jaringan smart grid untuk menyelesaikan masalah tersebut. Blockchain merupakan sebuah rekaman autentik dari seluruh aktivitas yang terjadi dalam suatu jaringan, tersebar di seluruh komponen jaringan, dan saling terkait dalam suatu rangkaian blok data [6]. Blockchain dapat diasumsikan sebagai arsip transaksi yang dikumpulkan pada blok-blok dengan penanda waktu atau timestamp. Setiap blok juga teridentifikasi dengan suatu nilai hash. Namun, setiap blok tersebut mereferensikan nilai hash dari blok yang ada sebelumnya.

Fungsi hash merupakan suatu fungsi matematika yang mengambil masukan panjang variabel dan mengubahnya ke dalam urutan biner dengan panjang yang tetap. Fungsi ini digunakan pada berbagai aplikasi pengamanan dan protokol internet. Beberapa contoh kegunaannya adalah untuk autentikasi pesan, tanda tangan digital, dan penyimpanan password [7].

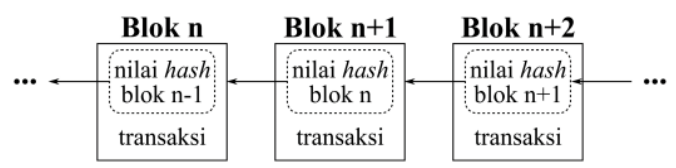

Gambar 1. Model sederhana blockchain.

Sistem kriptografi diterapkan untuk mengamankan data yang dikirimkan sehingga data tersebut hanya bisa diakses oleh pengirim dan penerima. Kriptografi adalah ilmu dan seni untuk menjaga keamanan pesan ketika pesan tersebut dikirim dari suatu tempat ke tempat lain [8].

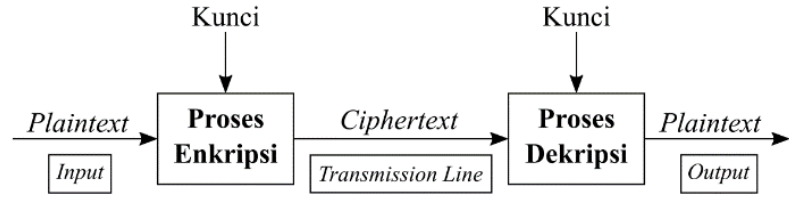

Gambar 2. Model sederhana kriptografi.

Skema yang digunakan pada penelitian ini adalah kriptografi asimetris bernama RSA. RSA memodelkan plaintext dan ciphertext menjadi sebuah bilangan bulat [9]. RSA memanfaatkan prinsip dari eksponensial dan aritmetika modular. Plaintext dienkripsi dalam blok-blok yang 
mempunyai ukuran dengan nilai biner tertentu. Setelah itu, blok data diolah menggunakan rumus berikut:

$$
C=M^{e} \bmod (n) ; M=C^{d} \bmod (n)
$$

$C$ adalah blok data ciphertext dan $M$ adalah blok data plaintext. Pengirim dan penerima mengetahui nilai dari $n$ dan $e$. Namun, nilai $d$ hanya diketahui oleh penerima. Oleh karena itu, RSA ini berupa algoritma enkripsi asimetris atau kunci-publik dengan kunci umum $P U=[e, n]$ dan kunci privat $P R=[d, n]$.

Nilai $n$ didapatkan dari perkalian bilangan prima $p$ dan $q$ dengan $p \neq q$. Lalu, $\Phi(n)$ dihitung dengan rumus $\phi(n)=$ $(p-1)(q-1)$. Nilai $e$ dipilih sehingga memenuhi $\operatorname{FPB}(\phi(n), e)=1$ dan $1<e<\phi(n)$. Sedangkan nilai $d$ dicari sehingga memenuhi $e \cdot d \equiv 1(\bmod (\phi(n)))$.

Salah satu variabel penting yang terdapat pada RSA adalah pemilihan ukuran kunci yang digunakan. Ukuran kunci yang terlalu kecil akan memudahkan sistem untuk bisa dibobol oleh pihak yang tidak bertanggung jawab. Oleh karena itu, National Institute of Standards and Technology (NIST) memberikan rekomendasi untuk tidak menggunakan kunci yang berukuran 1024 bit atau yang lebih kecil untuk pengamanan informasi penting di pemerintahan [10].

Sistem yang baru diciptakan tersebut harus bisa menyesuaikan frekuensi pengambilan data pada jaringan smart grid. Penelitian ini akan merancang suatu simulasi dari jaringan smart grid secara sederhana dengan menerapkan blockchain dan kriptografi untuk mengetahui pengaruh dari variabel yang terdapat pada keduanya. Simulasi dilakukan dengan menggunakan aplikasi MATLAB, yang tersusun dari program kriptografi menggunakan algoritma RSA dan program pembuatan blockchain sederhana.

Penelitian ini memiliki beberapa batasan atau asumsi untuk mempermudah penyelesaian masalah, seperti saluran transmisi dianggap bersifat sempurna atau tidak menimbulkan galat pada data yang ditransmisikan, penggunaan skema RSA, jaringan mempunyai jumlah klien tetap, dan simulasi tidak dilakukan menggunakan perangkat smart meter yang sebenarnya, tetapi hanya menggunakan laptop dan komputer.

Tujuan utama dari penelitian ini adalah mendapatkan waktu komputasi yang dibutuhkan oleh program blockchain dan kriptografi pada suatu model jaringan smart grid. Selain itu, penelitian ini bertujuan untuk mengetahui pengaruh lainnya yang dapat ditimbulkan oleh perubahan variabel yang terdapat pada blockchain dan algoritma RSA.

Penelitian ini diharapkan dapat memberikan manfaat seperti pemahaman kriptografi dan aplikasinya pada dunia nyata. Selain itu, penelitian ini ingin membuktikan bahwa blockchain bukanlah topik yang terlalu susah dan kompleks untuk dipelajari oleh mahasiswa tingkat sarjana. Di sisi lain, smart grid juga merupakan contoh baik untuk penelitian karena dapat menggabungkan dua jenis bidang studi, yaitu bidang telekomunikasi dan bidang sistem tenaga.

\section{URAIAN PENELITIAN}

\section{A. Peninjauan Pustaka}

Peninjauan pustaka dilakukan untuk mencari kondisi terkini dari topik yang sejenis dengan penelitian ini. Beberapa topik seperti kriptografi, blockchain, dan smart grid telah menghasilkan banyak paper yang telah dipublikasikan. Sehingga, penelitian ini dapat menjadi tambahan atau pelengkap dari penelitian yang telah dilakukan.

\section{B. Desain Sistem}

Program awalnya disusun berdasarkan dua fungsi utama yang akan diterapkan pada jaringan, yaitu fungsi RSA dan fungsi hash. Kedua fungsi ini berguna untuk mengamati pengaruh variabel penting pada fungsi terhadap waktu komputasi yang dibutuhkan untuk satu pengguna. Waktu yang diamati adalah lamanya fungsi untuk mengolah satu nilai masukan hingga menghasilkan keluaran.

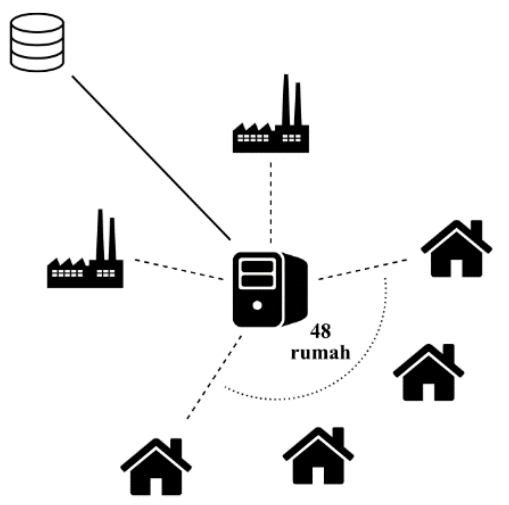

Gambar 3. Desain jaringan smart grid lokal yang disimulasikan.

Setelah itu, sebuah jaringan smart grid dirancang sebagai asumsi penerapan program yang disusun. Jaringan tersusun dari 48 rumah dan dua pabrik yang terhubung dengan server lokal. Selain itu, server lokal terhubung dengan sebuah database. Database ini berperan dalam penyimpanan data yang menggunakan sistem blockchain. Topologi jaringan yang digunakan pada penelitian ini adalah star topology atau topologi bintang. Topologi jenis ini dipilih karena penelitian ini diasumsikan hanya pada skala lokal.

Pada komunikasi antara dua perangkat, terdapat sebuah protokol yang harus dipenuhi. Hal itu dikarenakan prosedur yang terlibat dapat menjadi rumit sehingga kesepakatan tingkat tinggi dibuat di antara dua perangkat. Salah satu arsitektur yang sering digunakan adalah Transmission Control Protocol dan Internet Protocol yang membentuk rangkaian protokol TCP/IP. Protokol ini yang menjadi dasar dari sistem internet. Arsitektur lainnya yang cukup dikenal tetapi jarang digunakan adalah model Open Systems Interconnection (OSI) [11].

\begin{tabular}{|c|c|}
\hline Application & \multirow{2}{*}{ Application } \\
\hline Presentation & \\
\hline Session & \multirow{2}{*}{$\begin{array}{c}\text { Transport } \\
\text { (host-to-host) }\end{array}$} \\
\hline Transport & \\
\hline Network & Internet \\
\hline Data link & Network access \\
\hline Physical & Physical \\
\hline
\end{tabular}

Gambar 4. Perbandingan layer pada model OSI dan model TCP/IP. 
Program yang dibuat dalam penelitian ini akan menjadi salah satu komponen dalam jaringan smart grid. Karena jaringan tersebut bekerja layaknya jaringan telekomunikasi lainnya, program akan dirancang untuk bisa kompatibel dengan desain jaringan telekomunikasi yang sudah ada. Program pertama yang berupa fungsi RSA diletakkan dekat dengan raw data atau data kasar. Lalu, program kedua yang berupa fungsi hash diletakkan sebelum proses penyimpanan oleh server.

\section{Perancangan Program}

Program yang telah berjalan dengan baik nantinya akan diuji dengan menjalankan program secara berulang-ulang. Hal tersebut dimaksudkan untuk mendapatkan rangkuman hasil dari setiap jenis program yang telah dibuat.

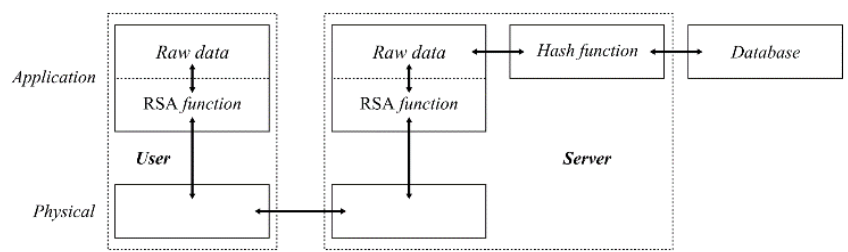

Gambar 5. Skema lengkap dari penerapan program pada komunikasi dengan prinsip end-to-end antara user dan server.

Pada program RSA yang dibuat untuk jaringan smart grid ini, program terdiri dari beberapa informasi dan variabel yang didefinisikan terlebih dahulu, yaitu:

1. Raw data string yang memuat beberapa informasi yang dipisahkan oleh tanda pagar. Informasi tersebut memiliki panjang maksimal 32 karakter yang terdiri dari kode identifikasi pelanggan, unix time, pemakaian listrik, dan daya terukur. Contoh string yang dihasilkan: AP24V0\#1543509173\#123456\#1234.56

2. Pengambilan data pada jaringan smart grid diasumsikan akan dilakukan setiap satu menit.

3. Ukuran kunci RSA yang digunakan untuk rumah adalah 1536 bit dan untuk pabrik adalah 3072 bit.

4. Keluaran dari fungsi enkripsi berupa matriks baris dari bilangan yang sebanding dengan kunci. Sehingga, untuk rumah berukuran $1 \times 192 \times 8$-bit signed integer dan pabrik berukuran 1 × 384 × 8-bit signed integer.

5. Satu siklus didefinisikan dengan pengiriman data dari tiap pengguna menuju server dan sebaliknya. Untuk pengiriman dari server, data string memuat kode identifikasi pelanggan, kode perintah, dan karakter pengisi dengan jumlah karakter maksimal 32 karakter. Contoh string yang dihasilkan:

AP2 4X1\# 25 \#XXXXXXXXXXXXXXXXXXXXXX

Sedangkan program hash yang dibuat untuk jaringan smart grid merepresentasikan proses penyusunan blok dari blockchain oleh server. Program ini disendirikan karena program ini akan memerlukan waktu yang lebih lama jika dibandingkan dengan program sebelumnya. Hal ini dikarenakan adanya ketentuan yang dibuat untuk nilai hash yang diinginkan. Sebagai contoh, nilai hash berikut yang memenuhi ketentuan tiga digit nol:

0 0 0B5B89851DA6EDB 6427C25D5CCA7600F18 9ADF 002C737B1A29E1E060ADF56F
Kegunaan nilai hash yang harus memenuhi suatu ketentuan bertujuan sebagai proof of work sebagai bukti bahwa pekerjaan untuk menghitung nilai hash telah dilakukan untuk sebuah masukan string.

Proses yang dilakukan pada kode program fungsi hash ini hampir sama dengan cara pada transakasi Bitcoin, tetapi sistem pada Bitcoin mengharuskan nilai hash yang dihasilkan berada di bawah suatu nilai atau dikenal dengan istilah target. Sebagai perbandingan, nilai target saat ini memiliki awalan nol untuk 18 digit pertama [12].

\section{ANALISIS DAN PEMBAHASAN DATA}

\section{A. Ukuran Kunci RSA}

Gambar 6 memberikan gambaran persebaran data yang didapatkan untuk beberapa ukuran kunci RSA. Setiap nilai ukuran kunci dilakukan pengukuran sebanyak 20 kali. Sedangkan rentang nilai ukuran kunci yang diuji adalah dari 1536 bit hingga 4092 bit dengan interval 64 bit. Dari Gambar 6 , terlihat bahwa dengan semakin besarnya ukuran kunci mengakibatkan waktu komputasi cenderung lebih bervariasi. Selain itu, pergerakan nilai rata-rata waktu komputasi menunjukkan tren naik di setiap ukuran kunci. Meskipun terjadi fluktuasi pada kenaikan yang terjadi, hal tersebut masih dapat menjadi bukti bahwa ukuran kunci RSA berpengaruh secara eksponensial terhadap waktu komputasi yang dibutuhkan.

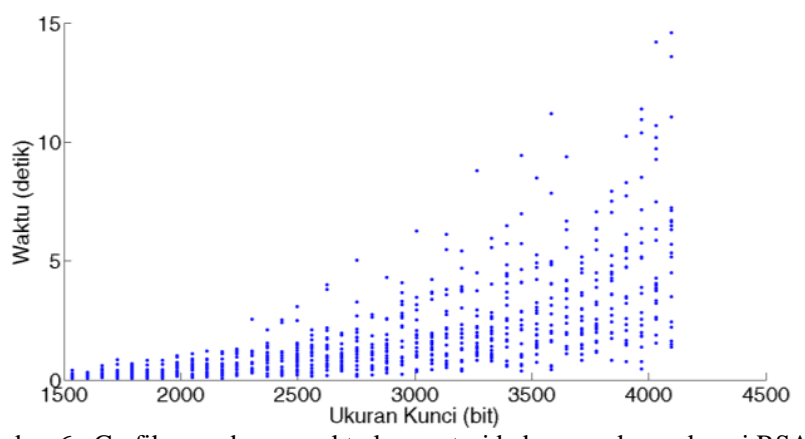

Gambar 6. Grafik persebaran waktu komputasi beberapa ukuran kunci RSA.

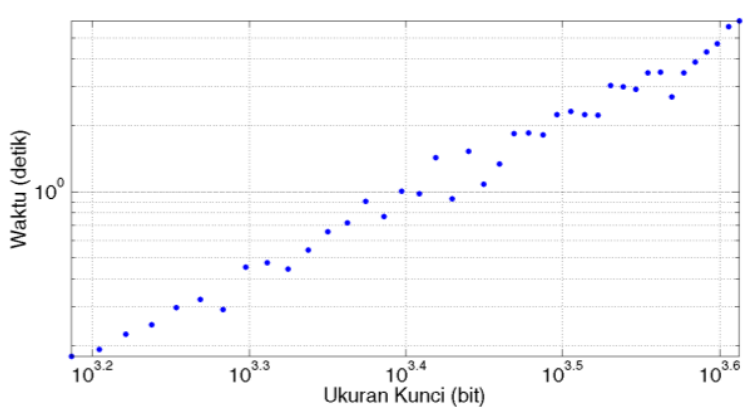

Gambar 7. Grafik "log-log” rata-rata waktu komputasi setiap ukuran kunci.

\section{B. Ketentuan Nilai Hash}

Pengujian ketentuan nilai hash dilakukan dengan menghitung waktu yang dibutuhkan untuk mencari satu nilai hash yang memenuhi ketentuan berupa jumlah digit nol yang mengawali nilai hash tersebut. Jumlah digit nol yang dipilih sebanyak dua, tiga, dan empat digit. Setiap ketentuan dijalankan sebanyak 250 kali. 
Tabel 1.

Rangkuman pengaruh ketentuan nilai hash terhadap waktu komputasi

\begin{tabular}{cccc}
\hline \hline Nama Variabel & 2 Digit Nol & 3 Digit Nol & 4 Digit Nol \\
\hline Waktu Minimum & 0,001114 & 0,000808 & 0,470296 \\
Rata-rata & 0,096102 & 1,53117 & 21,98469 \\
Waktu Maksimum & 0,458466 & 7,751967 & 137,1826 \\
Simpangan Baku & 0,090674 & 1,517616 & 20,37014 \\
\hline \hline *angka dalam detik & & &
\end{tabular}

*angka dalam detik

Dari data yang didapatkan pada Tabel 1, terlihat bahwa dengan semakin banyaknya digit nol yang menjadi ketentuan awalan nilai hash, rata-rata waktu komputasi yang dibutuhkan juga semakin lama. Selain itu, dengan bertambahnya satu digit nol, rata-rata waktu yang didapatkan juga terlihat naik dengan kelipatan tertentu.

Gambar 8 menunjukkan model persebaran data yang didapatkan untuk fungsi hash ini bersifat condong kanan (skewed right). Sifat tersebut menunjukkan data memiliki "ekor" kanan yang lebih panjang. Dengan kata lain, distribusi data pada sifat ini terpusat di sebelah kiri grafik dan lebih banyak datum yang berada di bawah nilai rata-rata data.

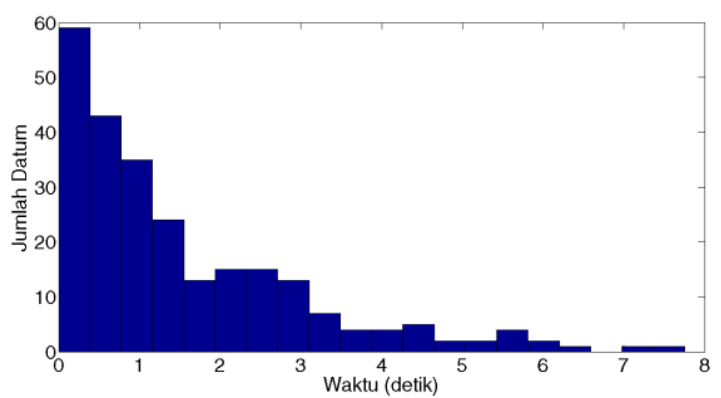

Gambar 8. Histogram untuk ketentuan tiga digit nol.

\section{Kinerja Program RSA}

Program RSA dalam penelitian ini tersusun oleh 50 kali proses enkripsi dan dekripsi untuk pengiriman informasi listrik pelanggan dari pengguna ke server beserta 50 kali proses yang sama untuk pengiriman kembali informasi perintah dari server ke pengguna. Jumlah proses tersebut menyesuaikan jumlah pengguna yang berada dalam jaringan yang diasumsikan.

Dalam penelitian yang telah dilakukan, program berhasil melakukan proses enkripsi dan dekripsi dari seluruh data. Hal tersebut dikarenakan pesan yang dikirimkan sudah sama persis dengan pesan yang diterima.

Program RSA telah dijalankan sebanyak 250 kali dan hasilnya terangkum pada Gambar 9 dan Tabel 2. Gambar 9 menunjukkan bahwa persebaran data yang didapatkan selama simulasi bersifat condong kanan dengan kelompok datum terbanyak berada di kisaran 10,5 detik.

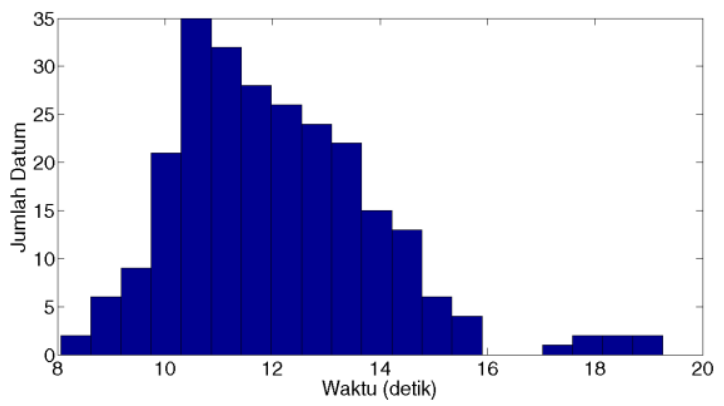

Gambar 9. Histogram simulasi program RSA.
Tabel 2.

Rangkuman data simulasi program RSA

\begin{tabular}{cccc}
\hline \hline Waktu Minimum & Rata-rata & Waktu Maksimum & Simpangan Baku \\
\hline 8,0604 detik & 12,0723 detik & 19,2570 detik & 1,9086 detik \\
\hline \hline
\end{tabular}

Jika pengambilan data pada jaringan smart grid diasumsikan akan dilakukan setiap satu menit, program RSA ini dapat dinyatakan layak untuk diterapkan pada model jaringan yang telah ditentukan. Hal itu dikarenakan rentang waktu yang dihasilkan oleh program masih lebih cepat dari asumsi frekuensi pengambilan data yang ditentukan.

\section{Kinerja Program Blockchain}

Program blockchain dalam penelitian ini tersusun oleh 50 buah string yang disusun untuk menghasilkan blockchain sederhana. Nilai hash dari blok pertama atau genesis block diatur menjadi seluruhnya berupa nol sebanyak 64 digit. Nilai tersebut menjadi acuan untuk pembentukan blok selanjutnya.

Dalam penelitian yang telah dilakukan, program berhasil untuk menyusun blockchain sederhana. Sebagai contoh, berikut ini adalah tiga blok pertama yang menjadi keluaran program: 00000000000000000000000000000000 \#UWTYK 6\#1 $541955600 \# 437.57$ \#335.16\#GLLL4 4B3E2A0 PO 7F OAR8 JDXRU37A 4 I

00044 A A ACE 6E 68DFDBE76021CB51B921\#YJDK4X\# 1 541955600 \# 60.782 \#331.027\#OQURQNWPW1LC8OFH JPOXAR5C5F55EI

000 C3530C0BF3D21 7D2 4A 8D50 9D8 4CF2 \#MES 6WX\# 1 541955600 4.9992\#57.3303\#NO2D9T211KPSELGY JC29V1 IBCO0D7U

Setiap blok tersebut tersusun dari: 32 digit pertama dari nilai hash blok sebelumnya; raw data string yang tersusun atas kode pelanggan, kode waktu, besar pemakaian listrik, dan besar daya listrik; terakhir adalah tambahan karakter acak untuk pemenuhan ketentuan nilai hash (nol pada tiga digit pertama). Secara keseluruhan, satu blok dalam blockchain sederhana ini tersusun dari 96 karakter termasuk tanda pagar.

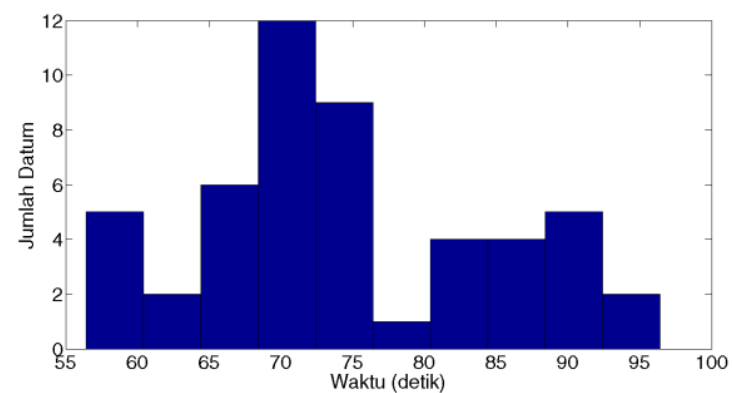

Gambar 10. Histogram simulasi program blockchain.

Gambar 10 memberikan gambaran persebaran data yang didapatkan selama simulasi program blockchain pada jaringan. Program hanya dijalankan sebanyak 50 kali dikarenakan kepastian yang didapatkan dari hasil simulasi program hash untuk tiap individu sebelumnya. Program blockchain yang digunakan pada jaringan menggunakan ketentuan tiga digit nol pada awal nilai hash. Waktu rata-rata yang didapatkan untuk tiap individu adalah sekitar 1,53 detik. Jika waktu tersebut dikalikan dengan 50, hasilnya adalah sekitar 75 detik mendekati rata-rata waktu komputasi yang terdapat pada Tabel 3. Waktu 
tersebut telah melampaui asumsi pengambilan data pada jaringan yang dilakukan setiap satu menit.

Tabel 3.

Rangkuman data simulasi program blockchain

\begin{tabular}{cccc}
\hline \hline Waktu Minimum & Rata-rata & Waktu Maksimum & Simpangan Baku \\
\hline 56,4208 detik & 74,6123 detik & 96,3993 detik & 10,4414 detik \\
\hline \hline
\end{tabular}

Namun, lamanya waktu menjalankan program blockchain tersebut tidak bisa menggambarkan keadaan yang sebenarnya jika diterapkan secara langsung pada suatu jaringan smart grid. Hal tersebut dikarenakan program penyusunan blockchain dapat dilakukan oleh perangkat yang mempunyai spesifikasi lebih baik dari komputer pada umumnya. Perangkat tersebut memang dikhusukan untuk melakukan pekerjaan dengan intensitas tinggi seperti pada server.

\section{KESIMPULAN/RINGKASAN}

\section{A. Kesimpulan}

Ukuran kunci pada sistem kriptografi RSA berpengaruh secara eksponensial terhadap waktu komputasi yang dibutuhkan. Sehingga, besarnya ukuran kunci yang terlalu besar tidak disarankan untuk digunakan secara praktis. Namun, ukuran kunci yang terlalu kecil juga tidak disarankan karena kemungkinan pembobolan menjadi lebih tinggi.

Perhitungan nilai hash pada pembentukan blockchain membutuhkan waktu yang semakin lama seiring dengan semakin sulitnya ketentuan yang perlu dipenuhi. Pengaruh penambahan satu digit yang berulang pada ketentuan mengakibatkan perubahan yang signifikan terhadap waktu pencarian nilai hash.

Penerapan program RSA dan blockchain dapat diterapkan pada model jaringan smart grid yang memiliki topologi bintang atau pohon. Di bidang kelistrikan, distribusi listrik pada smart grid menggunakan pola radial.

Peletakan program RSA pada application layer memungkinkan program dapat diletakkan pada berbagai jenis jaringan seperti TCP/IP. Selain itu, pembentukan blockchain yang hanya dikhusukan pada suatu perangkat memungkinkan adanya pembagian tanggung jawab dalam penggunaan data.

Kriptografi menggunakan RSA dapat memberikan keamanan pada jaringan smart grid dengan merahasaikan transmisi data antara pelanggan dan server. Di sisi lain, pembentukan blockchain dapat memberikan keamanan tambahan saat penyimpanan data dalam database.

Simulasi program yang telah dijalankan perlu dikembangkan dengan lebih lanjut pada jaringan smart grid lainnya karena adanya perbedaan perangkat dan aplikasi yang akan digunakan. Aplikasi MATLAB yang dipakai pada penelitian ini tidak bisa diterapkan secara langsung pada beberapa perangkat. Selain itu, jenis perangkat yang digunakan pada jaringan smart grid akan memiliki spesifikasi yang berbeda dengan perangkat yang digunakan selama penelitian.

\section{B. Saran}

Pengujian sistem kriptografi lainnya seperti Advanced Encryption Standard (AES) dapat dilakukan untuk mengetahui waktu komputasi yang dibutuhkan.
Jenis perangkat yang digunakan perlu lebih menyesuaikan dengan kondisi sebenarnya pada suatu jaringan smart grid.

Program perlu disusun ulang dengan tidak menggunakan MATLAB agar bisa diterapkan di lebih banyak jenis perangkat.

Simulasi secara real-time perlu dilakukan antara dua perangkat dengan menggunakan protokol tertentu seperti TCP/IP.

Perlunya simulasi dari model jaringan yang berbeda untuk beberapa perangkat yang terhubung dalam satu jaringan.

Pembentukan blockchain yang lebih kompleks perlu dibuat untuk bisa memuat lebih banyak informasi.

\section{LAMPIRAN}

Fungsi dasar RSA [13]

import javax.crypto.Cipher;

plaintext $=$ 'foobar';

cipher $=$ Cipher.getInstance ('RSA');

keygen

java.security.KeyPairGenerator.getInstanc

e ('RSA');

keyPair = keygen.genKeyPair();

cipher.init (Cipher.ENCRYPT_MODE,

keyPair.getPrivate());

plaintextUnicodeVals

uint16 (plaintext);

plaintextBytes

typecast (plaintextunicodeVals, 'int8');

ciphertext

cipher.doFinal (plaintextBytes)'

cipher.init (Cipher.DECRYPT_MODE,

keyPair.getPublic());

decryptedBytes

cipher.doFinal (ciphertext);

decryptedText

char (typecast (decryptedBytes, 'uint16'))'

Fungsi dasar pencarian nilai hash

data

'kvIf7\#KHAPO\#20180827T020745Z\#A\#12345.67\#

$1234.56 \#^{\prime}$;

prev hash

. 0000000000000000000000000000000000000000

$000000000000000000000000{ }^{\prime}$;

string = add_chara (prev_hash, data);

sha256hasher

System. Security. Cryptography. SHA256Manage

d;

sha256

$=$

uint8 (sha256hasher. ComputeHash (uint8 (stri

ng)) ) ;

while sha256(1) =0 || $\operatorname{sha256(2)>=16}$ string = add_chara (prev_hash, data); sha256

uint8 (sha256hasher. ComputeHash (uint8 (stri

ng)) );

end

hash $=$ reshape $\left(\operatorname{dec} 2 \text { hex }(\operatorname{sha} 256)^{\prime}, 64,1\right)^{\prime}$; 
Fungsi penambahan karakter acak pada program hash

function string = add_chara (prev, data)

symbols = ['A':'Z' 'O':'9'];

stLength $=62$-length (data);

nums $=$ randi (numel (symbols), $[1$

stLength]);

st $=$ symbols (nums);

prev_cut $=\operatorname{prev}(1: 32)$;

string

strcat (prev_cut,' '\#', data, '\#', st) ;

end

Contoh penggunaan fungsi tic dan toc dalam fungsi for untuk pengukuran waktu komputasi secara berulang

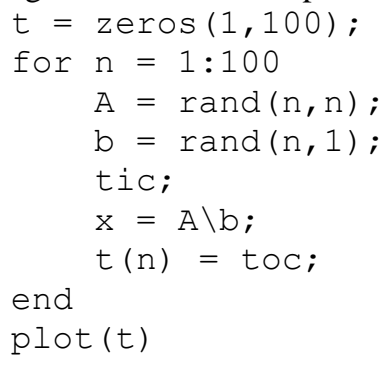

\section{DAFTAR PUSTAKA}

National Institute of Standards and Technology, "NIST Framework and Roadmap for Smart Grid Interoperability Standards, Release
3.0," 2014.

[2] S. V. Nandury and B. A. Begum, "Big Data for Smart Grid Operation in Smart Cities," in IEEE International Conference on Wireless Communications Signal Processing and Networking (WiSPNET), 2017.

[3] Laboratory for Advanced System Software, "Smart - UMass Trace Repository," $2018 . \quad$ [Online]. Available: http://traces.cs.umass.edu/index.php/Smart/Smart.

[4] The Research Perspective Ltd, "Smart Meter Electricity Trial Data Manifest," 2012.

$=\quad[5] \quad$ J. Gao et al., "GridMonitoring: Secured Sovereign Blockchain Based Monitoring on Smart Grid," IEEE Access, vol. 4, pp. 2292-2303, 2018.

[6] K. Christidis and M. Devetsikiotis, "Blockchains and Smart Contracts for the Internet of Things," IEEE Access, vol. 4, pp. 22922303, 2016.

[7] W. Stallings, Cryptography and Network Security: Principles and Practice. Boston: Prentice Hal, Inc, 2011.

[8] D. Ariyus, Pengantar Ilmu Kriptografi: Teori, Analisis, dan Implementasi. Yogyakarta: Andi, 2008.

[9] R. L. Rivest, A. Shamir, and L. Adleman, "A Method for Obtaining Digital Signatures and Public-Key Cryptosystems," Commun. ACM, vol. 21, pp. 120-126, 1978.

[10] E. Barker, Recommendation for Key Management, Part 1: General, Revision 4. Gaithersburg: Gaithersburg National Institute of Standards and Technology, 2016.

[11] W. Stallings, Data and Computer Communications, 10th ed. New Jersey: Prentice Hal, Inc, 2015.

[12] G. Walker, "Learn Me a Bitcoin - Target," learnmeabitcoin.com, $2016 . \quad$ [Online]. Available: http://learnmeabitcoin.com/glossary/target.

[13] A. Janke, "encryption - RSA code in matlab," stackoverflow.com, 2012. [Online]. Available: https://stackoverflow.com/a/9436658. 